This document has been downloaded from

TamPub - The Institutional Repository of University of Tampere

\title{
Post-print
}

The permanent address of the publication is http://urn.fi/URN:NBN:fi:uta-201505121410

Author(s): Minkkinen, Jaana

Title: Associations between school-related factors and depressive symptoms among children : A comparative study, Finland and Norway

Year: $\quad 2014$

Journal Title: School Psychology International

Vol and number:

$35: 5$

Pages: $\quad 463-474$

Discipline: Psychology

School

/Other Unit:

School of Social Sciences and Humanities

Item Type: Journal Article

Language: en

DOI: $\quad$ http://dx.doi.org/10.1177/0143034313511008

URN: $\quad$ URN:NBN:fi:uta-201505121410

All material supplied via TamPub is protected by copyright and other intellectual property rights, and duplication or sale of all part of any of the repository collections is not permitted, except that material may be duplicated by you for your research use or educational purposes in electronic or print form. You must obtain permission for any other use. Electronic or print copies may not be offered, whether for sale or otherwise to anyone who is not an authorized user. 
Associations between school-related factors and depressive symptoms among children: A comparative study, Finland and Norway

\section{Jaana Minkkinen}

University of Tampere, Finland

Correspond with JaanaMinkkinen, School of Social Sciences and Humanities, FIN33014, University of Tampere, Finland

Email: jaana.minkkinen@uta.fi 


\section{Abstract}

This study compares school-related associations in depressive symptoms among children aged between 9-13 years from four schools in Finland and Norway. A total of 523 pupils participated in the cross-sectional survey. The connections between depressive symptoms and school factors were analysed using hierarchical regression analyses. School variables were self-perceived peer victimization, teacher and peer social support, school performance, and teachers' reports on competence in core subjects; these variables explain 30\% of the variance of the children's depressive symptoms in Norway and 26\% in Finland beyond that afforded by differences in the background characteristics and protective factors in the family. A trend was found in the Norwegian data which showed that poor relationships at school are connected more strongly with depressive symptoms than poor school performance, but the Finnish data did not confirm this. The results support the importance of taking various school factors into account with children suffering depressive symptoms, and not merely a dysfunctional domestic situation. The implications for school psychology practice are also discussed.

Keywords bulling, children, depression, depressive symptoms, Finland, Norway, peer victimization, school, school competence, school performance, social support, teacher 
Depression is detrimental to the mental and social well-being of children and adolescents. A clinically significant depressed mood is a comparatively rare disorder during childhood but the occurrence rises during puberty, especially among girls, and lifetime prevalence is up to $25 \%$ by the end of adolescence as documented in epidemiologic studies (Angold, Erkanli, Silberg, Eaves, \& Costello, 2002; Birmaher et al., 1996; Kessler, Avenevoli, \& Merikangas, 2001). Depressive disorders are highly associated with behavioral problems, somatic complaints, and other psychiatric disorders and behaviors, such as anxiety, suicide attempts, conduct disorder, and substance abuse (Birmaher et al., 1996; Eapen \& $\mathrm{C}^{`} \mathrm{rnc}^{`}$ ec, 2012). However, not only clinically significant depression but also 'subthreshold' depressive symptoms have connections to psychosocial impairment and the use of mental health services, and therefore the conceptualization of depression as a continuum is necessary (Angold, Costello, Farmer, Burns, \& Erkanli, 1999; Lewinsohn, Solomon, Seeley, \& Zeiss, 2000). In additional to the short-term problems, depression can have a negative longterm impact on mental health, including increased risk of suicide, abuse of alcohol and other substances, physical problems, disturbances in global functioning and interpersonal relationships, and the recurrence of depression in later adolescence and adulthood (Birmaher et al., 1996; Lewinsohn et al., 1994).

The causal connections of depression are proposed in abundance and can be divided into demographic, cultural, biological, psychiatric, and psychosocial factors such as maltreatment, poor familial functioning, stressful life events, and poor social support (Birmaher et al., 1996; Dobson \& Dozois, 2008; Tonmyr, Williams, Hovdestad, \& Draca, 2011). In the school environment, experiences of relationship impairments and poor school performance are recurrent for children and adolescents with depression (Birmaher et al., 1996). Peer victimization has been found to be particularly harmful, 
being a form of peer abuse where a child is frequently the target of peer aggression (Kochenderfer \& Ladd, 1996). A meta-analytic review of cross-sectional studies indicated that peer victimization is most strongly related to depression among 6 to 18year-olds (Hawker \& Boulton, 2000). Victimization seems to be a stronger predictor of self-reported symptoms of depression than vice versa although there is an evidence of reciprocity between victimization and depression (Fekkes et al., 2006; Sweeting, Young, West, \& Der, 2006). A theoretical explanation follows the diathesisstress model which suggests that external stressors create risk factors and prompt the onset of depressive symptoms (Bandura, Pastorelli, Barbaranelli, \& Caprara, 1999).

Furthermore, poor social support from other pupils is positively related to depressive symptoms in early adolescence (Glover, Burns, Butler, \& Patton, 1998; Jia et al., 2009). Poor social support from teachers or difficulties in a relationship with teachers have also been indicated to correlate with pre-adolescents’ depressive symptoms (Jia et al., 2009; Murray \& Greenberg, 2000; Reddy, Rhodes, \& Mulhall, 2003; Wang 2009). According to the epidemiological risk-buffer model, conditional characteristics such as social support function as protective factors and buffer the malign influence of stressors (Bandura et al., 1999). In summary, it might be proposed that the quality of relationships constitutes a continuum in relation to depressive symptoms including poor relationships or deficits in social support at one end, and good and warm relationships with sufficient social support at the other.

In addition to poor relationships at school, poor school performance is positively associated with depression in pre-adolescents (Owens, Stevenson, Hadwin, \& Norgate, 2012). However, the direction of the causal connection between school performance and depression varies in extant studies, and the research yields mixed findings. A substantial number of the studies support the connection between depression and poor academic 
performance (Fröjd et al., 2008; Kovacs \& Goldston, 1991; Kumpulainen et al., 1999) but several longitudinal analyses also show evidence of the trajectories from antecedent academic failures to depression (Masten et al., 2005; McCarty et al., 2008; Rothon et al., 2009). According to the reformulated learned helplessness model of depression, a person has a higher risk of succumbing to depression if he or she attributes negative experiences, such as low grades, to personal, comprehensive and stable aspects of him or herself (Abramson, Seligman, \& Teasdale, 1978). On the other hand, the trajectory from depressive symptoms to poor school performance has been explained mainly by lower ability to function due to depression (Beck, 1967).

While the associations of depressive symptoms with poor relationships and school performance are well documented, little attention has been paid to comparisons between various school factors correlating with levels of depressive symptomatology, and only two studies were found relating to this issue (Boulard, Quertemont, Gauthier, \& Born, 2012; Undheim \& Sund, 2005). Thus, there is quite limited extant knowledge concerning the proportional extents of the associations of different school factors with depressive symptoms. However, this kind of information would have great relevance, particularly for school psychologists and other school personnel.

The purpose of this study is to examine to what extent various school factors correlate with depressive symptoms and each other. Is there a significant difference between the quality of the relationships at school and school performance concerning their associations with children's depressive symptoms? The associations are studied among Finnish and Norwegian children in order to produce more extensive results by means of an international comparison. Although these two Nordic countries have similarities when it comes to national investments in a strong welfare state, including adequate standards of living and schooling for all citizens as well as similar social laws and 
regulations, national features also exist such as a different school starting age. However, it was predicted that poor relationships at school would have a stronger positive connection with depressive symptoms than poor school performance in both countries based on previous studies.

\section{Method}

\section{Participants}

The participants came from two elementary schools in Finland and two elementary schools in Norway, from the cities of Tampere and Trondheim, the third biggest cities in their respective countries. Schools were selected from different city districts, with one school from a high status area of the city and the other a low status area. The selection criteria for the schools were based on the social status of the housing area, unemployment rates, and other lifestyle indicators of the adult population, as defined in a similar survey in 2003 (Leiulfsrud et al., 2003). Nonetheless, it should be noted that the differences between the city districts were relatively slight both in Tampere and Trondheim, compared with many other cities elsewhere in Europe.

A total of 523 pupils aged between 9- and 13-years-old participated in the study. Finnish participants were in grades 3 to 6 , while Norwegian participants were in grades 4 to 7 due to the different school starting age in the two countries. Respondent rates were $87 \%$ in Finland and $80 \%$ in Norway. A total of 21 participants were excluded from the Norwegian survey due to missing Children’s Depression Inventory questionnaires, two of whom had an immigrant family background. The final sample comprised 265 Finnish and 237 Norwegian children, 47\% of whom were girls in Finland and 48\% of whom were girls in Norway. According to the Finnish education system, more $6^{\text {th }}$ graders participated in the Finnish sample (32\%) than in the Norwegian sample (21\%). 
In the Finnish sample, 51\% $(\mathrm{N}=136)$ of participants and $56 \%(\mathrm{~N}=133)$ in the Norwegian sample were from schools in the high status area. Twenty-three Finnish and 24 Norwegian participants had immigrant family backgrounds, and 22 were from the school in a low status area in both countries. A total of 15 Finnish and ten Norwegian classes participated in the study. There were significantly fewer pupils per class in Finland $(M=20)$ than in Norway $(M=32), p<0.001$ (t-test). However, in Norway there were two or three teachers per class and pupils were divided into two or three groups which had partly different timetables. On the other hand, the Finnish classes had only one teacher in general, but classes with pupils from an immigrant family had two teachers in many lessons.

\section{Procedure}

Participation in the study was voluntary and written consent was obtained from parents via information letters and consent slips sent to all pupils. The children were asked to complete questionnaires during a typical class with a teacher and the researcher present. The researcher presented the questions orally in the class and asked the children to write their answers. In addition, the children were informed that they could withdraw or choose to omit questions should they choose to do so. Respondents' and teachers’ questionnaires were submitted anonymously.

\section{Measures}

Depressive symptoms. Depressive symptoms were measured with the Short Form of the Children's Depression Inventory (CDI-S). CDI-S is a shorter version of the original CDI developed by Maria Kovacs and Aaron Beck (1977) and is a widely used indicator to measure depressive symptoms in the school-aged child and adolescent population. The validity of CDI-S has been shown to be high as a screening tool for depression in medically-ill children (Allgaier et al., 2012).The CDI-S has ten items 
measuring the cognitive, affective, and behavioral symptoms of depression (Kovacs, 2003). Participants in the present study were asked to report each item according to how often they experienced the symptom during the week prior to answering the questionnaire, whereas a two-week period is used in the original inventory. Item scores ranged from 0-2 and ratings were added together to obtain a total score. Lower total scores indicate few symptoms of depression while higher scores indicate more symptoms. Reliability was $\alpha=.79$ for the Finnish sample and $\alpha=.86$ for the Norwegian sample.

School related variables. School related variables are peer victimization, teacher social support, peer social support, school performance, and competence in core subjects. Peer victimization is composed of two items on tripartite scales. The items are 'Do other pupils in your class bully you?' (never/sometimes/often) and 'Other pupils do not bully me/bully me sometimes/bully me almost every day’. Teacher social support is composed of three items on tri-point scales. The items are 'Does the teacher understand when school work is difficult?’ (often/sometimes/never), 'Does the teacher understand when a pupil is feeling bad?’ (often/sometimes/never), and 'How important is the teacher at school?' (very important/quite important/unimportant or inappropriate). Peer social support was gauged with the question 'If you are happy or sad with whom are you able to talk?'. No friends to talk to indicates poor peer support. School performance was addressed with a question on how the children manage at school in their own opinion (fine/not fine). Competence in core subjects was based on the teacher's report on a five-point scale ( 1 = very poor readiness, 5 = very good readiness $)$.

Family protective factors. Protective factors in a family are parents to talk to, parental presence, and parent-child activities. Having parents to talk to was addressed with the question 'If you are happy or sad, with whom are you able to talk?' (no 
adults/adults to talk to at home). Parental presence was gauged with the question 'Were you at home without adults yesterday?' (scale from 0-4,where 4 indicates that the child had adults with him or her in the morning, afternoon, evening, and at night). Parentchild activities were addressed with the question 'Did you do something with your parents yesterday? (no/yes).

Background characteristics. Potentially confounding variables were analysed by performing a preliminary analysis of SPSS regression and SPSS frequencies separately for the Finnish and Norwegian data. The variables of gender, class size, immigrant family, and money at home were included in the further hierarchical regression analysis because they either predicted the number of depressive symptoms with the use of a criterion of $p<0.05$ for the beta-value, or mitigated or extended the regression weights of the school-related variables in the multiple regression analysis of the Finnish or Norwegian data. Gender and immigrant family are dichotomous variables reported by teachers. Immigrant family refers to at least one of the parents being an immigrant. Money at home was addressed with the question 'Does your family have the money to buy or do things when you want? (There is always plenty of/a fair amount of/always too little money at home/I can’t answer or I don’t know). The first option indicates plenty of money at home and other options are designed to reflect the fact that this is not the case. Gender in the Finnish data and class size in the Norwegian data were found to be suppressor variables enhancing the effects of self-perceived school performance, peer victimization, and teacher social support on the variable of depressive symptoms (Tabachnick \& Fidell, 2013).

\section{Data Analysis}

All of the statistical analyses were performed separately but similarly for the Finnish and Norwegian data using SPSS-20. Descriptive statistics for the CDI-S total score and 
the school-related variables were conducted for the country comparison. Models of the hierarchical regression analysis were executed to determine whether poor relationships at school or poor school performance were more likely predictors of children's depressive symptoms. Preliminary analyses of the assumptions of the hierarchical regression analysis led to some transformation of the variables to reduce skewness and the number of outliers, and also to improve the normality, linearity, and homoscedasticity of residuals (Tabachnick \& Fidell, 2013). Logarithmic transformation was used on the number of depressive symptoms and a square root transformation was used on the measures of peer victimization and teacher social support. The results of multicollinearity checks showed that the square root of the Variance Inflation Factor was well below the limit of 2 for all variables. No outliers among the cases were identified with the use of a $\mathrm{p}<0.001$ criterion for Mahalanobis distance. Missing data in the measurement of variables were substituted with means.

\section{Results}

\section{Descriptive Statistics}

The CDI-S total score ranged from 0-13 among the Finnish children and from 0-20 among the Norwegian children. Finnish children had more depressive symptoms than Norwegians ( $\mathrm{p}<0.01$ ); there was more peer victimization among the Finnish children ( $\mathrm{p}<0.01)$. Norwegian children obtained more social support from their peers $(\mathrm{p}<$ 0.001). On the other hand, teacher social support, self-perceived school performance, and competence in core subjects did not indicate any statistically significant differences between the two countries (see Supplemental Material; Table 1 for descriptive statistics). 
Table 1. Descriptive statistics of the CDI-S total score and school-related variables by country

\begin{tabular}{|c|c|c|c|c|c|c|c|c|c|}
\hline \multirow[t]{2}{*}{ Variables } & \multicolumn{4}{|c|}{ Finland } & \multicolumn{4}{|c|}{ Norway } & \multirow{2}{*}{$\begin{array}{l}\text { Country } \\
\text { differences }\end{array}$} \\
\hline & $M$ & $S D$ & $\alpha$ & $n$ & $M$ & $S D$ & $\alpha$ & $n$ & \\
\hline Depressive & 2.52 & 2.76 & 0.79 & 263 & 2.11 & 3.18 & 0.86 & 237 & $\mathrm{p}<0.01$ \\
\hline \multicolumn{10}{|l|}{ symptoms $^{\mathrm{a}}$} \\
\hline \multicolumn{10}{|l|}{ School-related } \\
\hline \multicolumn{10}{|l|}{ variables } \\
\hline Peer & 2.93 & 1.07 & 0.77 & 260 & 2.67 & 0.96 & 0.71 & 238 & $\mathrm{p}<0.01$ \\
\hline \multicolumn{10}{|l|}{ victimization $^{\mathrm{b}}$} \\
\hline Teacher & 6.67 & 1.50 & 0.65 & 261 & 6.70 & 1.52 & 0.58 & 234 & Ns \\
\hline \multicolumn{10}{|l|}{ social } \\
\hline \multicolumn{10}{|l|}{ support $^{\mathrm{C}}$} \\
\hline Peer social & 0.60 & 0.49 & & 265 & 0.78 & 0.42 & & 238 & $\mathrm{p}<0.001$ \\
\hline \multicolumn{10}{|l|}{ support $^{\mathrm{d}}$} \\
\hline Self- & 0.86 & 0.35 & & 265 & 0.89 & 0.32 & & 238 & Ns \\
\hline \multicolumn{10}{|l|}{ perceived } \\
\hline \multicolumn{10}{|l|}{ school } \\
\hline \multicolumn{10}{|l|}{ performance ${ }^{\mathrm{e}}$} \\
\hline Competence & 3.76 & 0.89 & & 262 & 3.83 & 1.10 & & 235 & Ns \\
\hline \multicolumn{10}{|l|}{ in core } \\
\hline subjects $^{\mathrm{f}}$ & & & & & & & & & \\
\hline
\end{tabular}

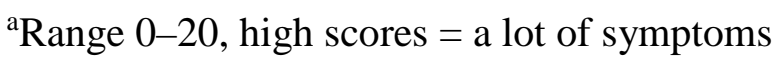


${ }^{\mathrm{b}}$ Range 2-6, high scores $=$ a lot of victimization

${ }^{\mathrm{c}}$ Range 3-9, high scores = very good support

${ }^{\mathrm{d}} 0=$ poor, 1 = good support

${ }^{\mathrm{e}} 0=$ poor, 1 = good performance

${ }^{\mathrm{f}}$ Range 1-5, high scores $=$ high competence

gIndependent-Samples Mann-Whitney U Test

\section{Comparing the Associations of the School Related Variables with Depressive}

\section{Symptoms}

Two models of hierarchical regression analysis were conducted to determine whether poor relationships at school or poor school performance were more likely predictors of the children's depressive symptoms. In both models, steps 1 and 2 were congruently conducted by country. In step 1, four background characteristics were analysed. In step 2, the measures of the protective factors in a family were included in the model. The bivariate correlation was significantly different from zero at the end of each step in the models, with the exception of step 2 in the Finnish data, indicating that protective factors in a family have no association with Finnish children’s depressive symptoms after the adjustment of the background characteristics. In Norway, on the other hand, a small number of protective factors in a family explain depressive symptoms among children enhancing the prediction of the symptoms by 7\% ( $<0.01)$. Background characteristics predict $9 \%(\mathrm{p}<0.001)$ of the variance of depressive symptoms among Finnish children and 4\% ( $<$ 0.05) among Norwegian children (see Supplemental Material; Table 2).

In Model 1, the measures representing the quality of the relationships at school were inserted into the equation in the third step. The variables significantly improved the 
squared multiple correlation coefficient in both datasets. The enhancement in $R^{2}$ was $19 \%$ in the analysis of the Finnish data and $26 \%$ in the Norwegian data (both $\mathrm{p}<0.001$ ). In Model 2, the school performance measures were inserted into the equation in the third step. The enhancement in $R^{2}$ was $10 \%$ in the analysis of the Finnish data and $9 \%$ in the Norwegian data (both $\mathrm{p}<0.001$ ).

Table 2. Summary of the two hierarchical regression models using total CDI-S scores (as a logarithmic transformation) as the dependent variable and Z-scores by country

\begin{tabular}{|c|c|c|c|c|c|c|c|c|c|c|c|c|c|c|}
\hline & \multicolumn{7}{|c|}{ Finland } & \multicolumn{7}{|c|}{ Norway } \\
\hline & $\mathrm{R}$ & $\mathrm{R}^{2}$ & Adj. $R^{2}$ & SE & $\Delta \mathrm{R}^{2}$ & F (Incr.) & df & $\mathrm{R}$ & $\mathrm{R}^{2}$ & Adj. & ${ }^{2} \mathrm{SE}$ & $\Delta \mathrm{R}^{2}$ & F (Incr.) & df \\
\hline \multicolumn{15}{|l|}{ Model 1} \\
\hline Step $1^{\mathrm{a}}$ & .29 & .09 & .07 & .72 & .09 & $6.01 * * *$ & 4,260 & .21 & .04 & .03 & .76 & .04 & $2.546 *$ & 4, 233 \\
\hline Step $2^{\mathrm{b}}$ & .33 & .11 & .09 & .71 & .03 & 2.51 & 3,257 & .33 & .11 & .09 & .74 & .07 & $6.03 * *$ & 3,230 \\
\hline Step $3^{c}$ & .55 & .30 & .27 & .64 & .19 & $23.02 * * *$ & 3,254 & .61 & .37 & .35 & .63 & .26 & $31.55 * * *$ & 3,227 \\
\hline \multicolumn{15}{|c|}{ Model 2 (Steps 1 and 2 as in Model 1) } \\
\hline Step $3^{\mathrm{d}}$ & .46 & .21 & .18 & .67 & .10 & $16.12^{* * *}$ & 2,255 & .45 & .20 & .17 & .71 & .09 & $12.61^{* * *}$ & 2, 228 \\
\hline Z-score ${ }^{\mathrm{e}}$ & \multicolumn{7}{|c|}{$1.54(\mathrm{p}=0.124)$} & \multicolumn{7}{|c|}{$2.64(p=0.008)$} \\
\hline
\end{tabular}

${ }^{a}$ Includes measures of gender, class size, immigrant family, money at home

${ }^{\mathrm{b}}$ Includes measures of parents to talk to, parental presence, parent-child activities

c Includes measures of peer victimization (sq. root), teacher social support (sq. root), peer social support

${ }^{\mathrm{d}}$ Includes measures of school performance and competence in core subjects

e Z-score indicates the difference of $\mathrm{R}$ between Models 1 and 2 in step 3

${ }^{*} \mathrm{p}<0.05 ; * * \mathrm{p}<0.01 ; * * * \mathrm{p}<0.001$

The difference in the bivariate correlation (R) between Model 1 and Model 2 is statistically significant in the Norwegian data $(\mathrm{p}=0.008)$. In other words, in Norway 
poor relationships at school have a significantly stronger association with children's depressive symptoms than poor school performance. However, in the Finnish data, poor school relationships do not have significantly more importance than poor school performance concerning the children’s depressive symptoms. Two possible explanations for the difference between countries can be considered. Either school performance is more important for Finnish children than it is for Norwegian children relative to its negative connection to depressive symptoms, or poor relationships at school are a greater risk for Norwegian children than Finnish children when it comes to depressive symptoms. In addition, both explanations may hold true simultaneously. The first explanation can be rejected on the strength of Model 2, which shows school performance as having a parallel linkage to the depressive symptoms in the countries. On the other hand, the second explanation gets support from Model 1 in that, poor relationships at school better explain depressive symptoms among Norwegians than among Finns. However, a more elaborate examination of the relationship variables would be required in order to standardize school performance in the equation as well. A third model of hierarchical regression analysis was carried out separately but similarly for the Finnish and Norwegian data in order to attain the specification about connections between depressive symptoms and single variables reflecting the school relationship. The background characteristics were analysed in the first step and protective factors in a family in the second step. In the third step, the variables of school relationships and school performance were examined (see Supplemental Material; Table 3). A comparison between countries with the unstandardized regression coefficients showed that all three relationship variables peer victimization, teacher social support, and peer social support have a stronger linkage with depressive symptoms in Norway than in Finland, which is parallel with the result from the previous analysis (see 
Supplemental Material; Table 2) although the differences between countries in single variables are not statistically significant (Z-scores not displayed in Table 3; see Supplemental Material; Table 3). One possible explanation for the country difference may be related to the amount of victimization and social support at school. A comparison between countries showed that the Norwegian children experienced more social support from their peers than the Finns ( $\mathrm{p}<0.001$; see Supplemental Material; Table 1), while there was no difference in perceived teacher support but more peer victimization among Finns than Norwegians ( $p<0.01$; see Supplemental Material; Table 1). 
Table 3. Hierarchical regression of background variables (step 1), protective factors in a family (step 2), and school variables (step 3) on total CDI-S scores ${ }^{\mathrm{a}}$ after step 3 by country

\begin{tabular}{|c|c|c|c|c|c|c|c|c|}
\hline \multirow[t]{2}{*}{ Independent variables } & \multicolumn{4}{|l|}{ Finland } & \multicolumn{4}{|l|}{ Norway } \\
\hline & $B$ & $S E$ & $\beta$ & $t$ & $B$ & $S E$ & $\beta$ & $t$ \\
\hline \multicolumn{9}{|l|}{ Background variables } \\
\hline Gender ${ }^{b}$ & -0.26 & 0.08 & -0.18 & $-3.29 * *$ & -0.07 & 0.08 & -0.04 & -0.79 \\
\hline Class size & -0.01 & 0.01 & -0.08 & -1.47 & 0.00 & 0.01 & 0.04 & 0.69 \\
\hline Immigrant family ${ }^{\mathrm{c}}$ & 0.30 & 0.14 & 0.12 & $2.21 *$ & 0.22 & 0.15 & 0.09 & 1.50 \\
\hline Money at home ${ }^{\mathrm{d}}$ & -0.26 & 0.08 & -0.16 & $-3.24 * *$ & -0.07 & 0.08 & -0.04 & -0.81 \\
\hline \multicolumn{9}{|c|}{ Protective factors in a family } \\
\hline Parents to talk to ${ }^{\mathrm{e}}$ & -0.01 & 0.10 & -0.00 & -0.06 & -0.08 & 0.12 & -0.04 & -0.67 \\
\hline Parental presence ${ }^{\mathrm{f}}$ & -0.06 & 0.05 & -0.06 & -1.19 & -0.05 & 0.06 & -0.05 & -0.97 \\
\hline Parent-child activities ${ }^{\mathrm{g}}$ & -0.11 & 0.08 & -0.07 & -1.39 & -0.17 & 0.10 & -0.09 & -1.69 \\
\hline \multicolumn{9}{|l|}{ School variables } \\
\hline \multicolumn{9}{|l|}{ Self-perceived school } \\
\hline performance & -0.54 & 0.12 & -0.25 & $-4.66 * * *$ & -0.48 & 0.13 & -0.20 & $-3.61 * * *$ \\
\hline \multicolumn{9}{|l|}{ Competence in core } \\
\hline subjects & -0.07 & 0.05 & -0.09 & -1.61 & -0.04 & 0.04 & -0.05 & -0.96 \\
\hline \multicolumn{9}{|l|}{ Peer victimization (sq. } \\
\hline root) & 0.98 & 0.13 & 0.39 & $7.67 * * *$ & 1.19 & 0.16 & 0.41 & $7.52 * * *$ \\
\hline \multicolumn{9}{|l|}{ Teacher social support } \\
\hline (sq. root) & -0.06 & 0.03 & -0.12 & $-2.30 *$ & -0.09 & 0.03 & -0.17 & $-2.90 * *$ \\
\hline Peer social support & -0.01 & 0.08 & -0.01 & -0.12 & -0.20 & 0.11 & -0.11 & -1.86 \\
\hline $\mathrm{R}^{2}$ & 0.38 & & & & 0.41 & & & \\
\hline Adjusted $\mathrm{R}^{2}$ & 0.35 & & & & 0.38 & & & \\
\hline$\Delta \mathrm{R}^{2}$ for step 3 & 0.27 & & & & 0.30 & & & \\
\hline F for step 3 & $21.42^{* * *}$ & & & & $23.20 * * *$ & & & \\
\hline$n$ & 265 & & & & 238 & & & \\
\hline
\end{tabular}

\section{${ }^{a}$ Logarithmic transformation}

${ }^{\mathrm{b}} 0=$ girl, 1 = boy 
${ }^{\text {c }} 0=$ native family, $1=$ at least one immigrant parent

${ }^{\mathrm{d}} 0=$ not plenty of money, $1=$ plenty of money

e $0=$ no adults to talk to when preadolescent is happy or sad, $1=$ adults to talk to

f $1-4$ ( 1 = an adult with a child at home the previous day either in the morning, afternoon, evening or at night, $4=$ an adult with a child at home the previous day in the morning, afternoon, evening and at night)

g $0=$ did nothing with parent yesterday, 1 = did something with parent yesterday

${ }^{*} \mathrm{p}<0.05 ; * * \mathrm{p}<0.01 ; * * * \mathrm{p}<0.001$

\section{Discussion}

The aim of this study was to demonstrate which factor has the stronger association with depressive symptoms among children: Poor school relationships or poor school performance. Data obtained from Finland and Norway yielded disharmonious results. The Norwegian data confirm the presupposition that poor relationships, including peer victimization and poor support from teachers and peers, have a more powerful positive connection to depressive symptoms than poor school performance. This result is parallel with Boulard and colleagues’ (2012) study, where being a target of verbal aggression has a clearly stronger association with a depressive mood than poor self-perceived academic achievement. Further, Undheim and Sund (2005) found an association between depressive symptoms and poor teacher support but no connection with depressive symptoms and poor self-perceived academic achievement among 12-yearold girls. More studies on the issue would be required to clarify the connections between school-related characteristics and depressive symptoms.

In addition, the present study indicated parallel results in both countries such as a strong connection between peer victimization and depressive symptoms consistent with 
previous cross-sectional studies among those aged between 9 and 13 (Juvonen, Graham, \& Schuster, 2003; Nadeem \& Graham, 2005; van der Wal, de Wit, \& Hirasing, 2003). The combined association of the school variables with depressive symptoms is relatively high in this study, indicating a considerable role for school factors among those aged between 9- and 13-years-old. The school variables explain $30 \%$ of the variance of the preadolescents’ depressive symptoms in Norway and 26\% in Finland beyond that afforded by differences in the background characteristics and protective factors in a family. What is noteworthy is that school factors better explain depressive symptoms than protective factors in a family in both countries, contrary to the expectations based on previous studies (Jia et al., 2009; Resnick et al., 1997).

\section{Limitations}

The strength of this study is the international comparative research frame, which provides information about the phenomenon across national characteristics. Further strengths are the high response rates and an established indicator of depression. However, the method of measuring depressive symptoms perceived only by children is always prone to bias due to a shorter low mood period than depression, and reporting the symptoms for only one week prior to the study could increase the bias. In addition, the results cannot be generalized due to the sample type, while the cross-sectional design limits the drawing of conclusions regarding causality. Further, the methodological solution applied here to place school-related variables as predictors of depressive symptoms was reasonable in order to compare the extent of the different school-related associations with depressive symptoms in parallel, but it is plausible that causalities could be more complex between schoolrelated variables and depression including mutual trends (Sweeting et al., 2006). 


\section{Conclusion and Implications}

This study shows that the quality of the relationships at school and self-perceived school performance should be taken into account seriously when considering depression among children aged between 9- and 13-years-old, and that it is not enough to merely observe difficulties at home. Additionally, a trend was found that poor relationships at school are associated significantly more strongly with depressive symptoms than poor school performance according to the Norwegian data. The knowledge of the relevance of the social context in school could be utilized when developing the measures of support provided by school psychologists for children experiencing depressive symptoms. In addition, a better understanding of the various school factors integrated within depression may help in identifying those pupils with mild to moderate depressive symptoms who are often a challenge to identify during everyday school activities.

\section{Note}

I would like to acknowledge the support received from Drs Irmeli Järventie and Atte Oksanen. This research was supported by a grant from the Finnish Cultural Foundation, Häme Regional fund. The data were collected in the Barndom og Skole i Velferdsstaten project (2009-2012 Norges Forskningsråd \& NTNU, Leiulfsrud). 


\section{References}

Abramson, L. Y., Seligman, M. E. P., \& Teasdale, J. D. (1978). Learned helplessness in humans: Critique and reformulation. Journal of Abnormal Psychology, 87(1), 49-74.

Angold, A., Costello, J., Farmer, E., Burns, B., \& Erkanli, A. (1999). Impaired but undiagnosed. Journal of the American Academy of Child and Adolescent Psychiatry, 38(2), 129-137.

Angold, A., Erkanli, A.,Silberg, J., Eaves, L., \& Costello, E. J. (2002). Depression scale scores in 8-17-year-olds: Effects of age and gender. Journal of Child Psychology and Psychiatry, 43(8), 1052-1063.

Allgaier, A-K., Frühe, B., Pietsch, K., Saravo, B., Baethmann, M., \& Schulte-Körne,G. (2012). Is the children's depression inventory short version a valid screening tool in pediatric care? A comparison to its full-length version. Journal of Psychosomatic Research, 73(5), 369-374, doi:

10.1016/j.jpsychores.2012.08.016.

Bandura, A., Pastorelli, C., Barbaranelli, C., \& Caprara, G. V. (1999). Self-efficacy pathways to childhood depression. Journal of Personality and Social Psychology, 76(2), 258-269.

Beck, A. T. (1967). Depression: Causes and treatment. Philadelphia: University of Pennsylvania Press.

Birmaher, B., Ryan, N. D., Williamson, D. E., Brent, D. A., Kaufman, J., Dahl, R. E., Perel, J., \& Nelson, B. (1996). Child and adolescent depression: A review of the 
past 10 years. Part I. Journal of the American Academy of Child and Adolescent Psychiatry, 35, 1427-1439.

Boulard, A., Quertemont, E., Gauthier, J-M., \& Born, M. (2012). Social context in school: Its relation to adolescents’ depressive mood. Journal of Adolescence, 35(1), 143-152, doi:10.1016/j.adolescence.2011.04.002.

Currie, C., Zanotti, C., Morgan, A., Currie, D., de Looze, M., Roberts, C., Samdal, O., Smith, O. R. F., Barnekow, V. (Eds.) (2012). Social determinants of health and well-being among young people. Health Behaviour in School-Aged Children (HBSC) study : international report from the 2009/2010 survey. Health Policy for Children and Adolescents, 6.

Dobson, K. S., \& Dozois, D. J. A. (2008). Introduction: Assessing risk and resilience in models of depression. In K. Dobson, \& D. Dozois (Eds.), Risk factors in depression (pp.1-16). Amsterdam: Elsevier Academic Press.

Eapen, V., \& Črnčec, R. (2012). Management of adolescent depression. Current opinion in psychiatry, 25(1), 7-13, doi: 10.1097/YCO.0b013e32834de3bd.

Fröjd, S. A., Nissinen, E. S., Pelkonen, M. U., Marttunen, M. J., Koivisto, A-M., \& Kaltiala-Heino, R. (2008). Depression and school performance in middle adolescent boys and girls. Journal of Adolescence, 31(4), 485-498, doi: 10.1016/j.adolescence.2007.08.006.

Glover, S., Burns, J., Butler, H. \& Patton, G. (1998). Social environments and the emotional wellbeing of young people. Family Matters, 49, 11-16. 
Hawker, D. S. J., \& Boulton, M. J. (2000). Twenty years’ research on peer victimization and psychosocial maladjustment: A meta-analytic review of cross-sectional studies. Journal of Child Psychology and Psychiatry, 41(4), 441-455.

Jia, Y., Way, N., Ling, G., Yoshikawa, H., Chen, X., Hughes, D., Ke, X., \& Lu, Z. (2009). The influence of student perceptions of school climate on socioemotional and academic adjustment: A comparison of Chinese and American adolescents. Child Development, 80(5), 1514-1530, doi: 10.1111/j.1467-8624.2009.01348.x.

Juvonen, J., Graham, S., \& Schuster, M. (2003). Bullying among young adolescents: The strong, the weak, and the troubled. Pediatrics, 112(6), 1231-1247.

Kessler, R.C., Avenevoli, S., \& Merikangas, K.R. (2001). Mood disorders in children and adolescents: An epidemiological perspective. Biological Psychiatry, 49(12), $1002-1014$.

Kochenderfer, B. J., \& Ladd, G. W. (1996). Peer victimization: cause or consequence of school maladjustment? Child Development, 67, 1305-1317.

Kovacs, M. (2003). Children’s Depression Inventory. Multi-Health Systems.

Kovacs, M., \& Beck, A. (1977). An empirical-clinical approach toward a definition of childhood depression. In J. Schulterbrandt, \& A. Raskin (Eds.), Depression in childhood: diagnosis, treatment and conceptual models (pp. 1-25). New York: Raven Press.

Kovacs, M., \& Goldston, D. (1991). Cognitive and social cognitive development of depressed children and adolescents. Journal of the American Academy of Child and Adolescent Psychiatry, 30, 388-392. 
Kumpulainen, K., Räsänen, E., Henttonen, I., Puura, K., Moilanen, I., Piha, J., Tamminen T., Almqvist F. (1999). Psychiatric disorders, performance level at school and special education at early elementary school age. European Child \& Adolescent Psychiatry, 8: Suppl. 4, IV/48-IV/54.

Leiulfsrud, H., Jensberg, H., Endresen, B., Dahl, Ø., Strand, I., Nilsen, E., \& Frisvold, B. (2003). Children's life-worlds: a comparative study of children's life chances and well-being in the Nordic countries. Norwegian National Report. Part 1: Documentation and Frequencies. Trondheim: Allforsk.

Lewinsohn, P. M., Roberts, R. E., Seeley, J. R., Rohde, P., Gotlib, I. H., \& Hops, H. (1994). Adolescent psychopathology: II. Psychosocial risk factors for depression. Journal of Abnormal Psychology, 103(2), 302-315.

Lewinsohn, P.M., Solomon, A., Seeley, J.R., \& Zeiss, A. (2000).Clinical implications of 'subthreshold’ depressive symptoms. Journal of Abnormal Psychology, 109(2), 345-351, doi: 10.1037//0021-843X.109.2.345.

Masten, A. M., Roisman, G. I., Long, J. D., Burt, K. B., Obradović, J., Riley, J. R., Boelcke-Stennes, K., \& Tellegen,A. (2005). Developmental cascades: Linking academic achievement and externalizing and internalizing symptoms over 20 years. Developmental Psychology, 41(5), 733-746, doi: 10.1037/00121649.41.5.733.

McCarty, C. A., Mason, W. A., Kosterman, R., Hawkins, J. D., Lengua, L. J., \& McCauley, E. (2008). Adolescent school failure predicts later depression among girls. Journal of Adolescent Health, 43(2), 180-187, doi:

10.1016/j.jadohealth.2008.01.023. 
Murray, C., \& Greenberg, M. (2000). Children's relationship with teachers and bonds with school. An investigation of patterns and correlates in middle childhood. Journal of School Psychology, 38(5), 423-445.

Nadeem, E., \& Graham, S. (2005). Early puberty, peer victimization, and internalizing symptoms in ethnic minority adolescents. Journal of Early Adolescence, 25(2), 197-222, doi: 10.1177/0272431604274177.

Owens, M., Stevenson, J., Hadwin, J. A., \& Norgate, R. (2012). Anxiety and depression in academic performance: An exploration of the mediating factors of worry and working memory. School Psychology International, 33(4), 433-449, doi: 10.1177/0143034311427433.

Reddy, R., Rhodes, J., \& Mulhall, P. (2003). The influence of teacher support on student adjustment in the middle school years: a latent growth curve study. Development and Psychopathology, 15(1), 119-138, doi: 10.1017.S0954579403000075.

Resnick, M., Bearman, P., Blum, R., Bauman, K., Harris, K., Jones, J., Tabor, J., Beuhring, T., Sieving, R., Shew, M., Ireland, M., Bearinger, L., \& Udry, J. R. (1997). Protecting adolescents from harm: Findings from the national longitudinal study on adolescent health. Journal of the American Medical Association, 278(10), 823-833.

Rothon, C., Head, J., Clark, C., Klineberg, E., Cattell, V., \& Stansfeld, S. (2009). The impact of psychological distress on the educational achievement of adolescents at the end of compulsory education. Social Psychiatry \& Psychiatric Epidemiology, 44(5), 421-427, doi: 10.1007/s00127-008-0452-8. 
Sweeting, H, Young, R., West, P., \& Der, G. (2006). Peer victimization and depression in early-mid adolescence: a longitudinal study. British Journal of Educational Psychology, 76(3), 577-594, doi: 10.1348/000709905X49890.

Tabachnick, B. G., \& Fidell, L. S. (2013).Using multivariate statistics. $6^{\text {th }}$ ed. Boston: Pearson Education.

Tonmyr, L., Williams, G., Hovdestad, W. E., \& Draca, J. (2011). Anxiety and/or depression in 10-15-year-olds investigated by child welfare in Canada. Journal of Adolescent Health, 48(5),493-498, doi: 10.1016/j.jadohealth.2010.08.009.

Undheim, A. M., \& Sund, A. M. (2005). School factors and the emergence of depressive symptoms among young Norwegian adolescents. European Child \&Adolescent Psychiatry,14(8), 446-453, doi: 10.1007/s00787-005-0496-1.

van der Wal, M. F., de Wit, C. A. M., \& Hirasing, R. A. (2003). Psychosocial health among young victims and offenders of direct and indirect bullying. Pediatrics, 111(6),1312-1317.

Wang, M-T. (2009). School climate support for behavioral and psychological adjustment: Testing the mediating effect of social competence. School Psychology Quarterly, 24 (4), 240-251, doi: 10.1037/a0017999. 